\title{
The Fractography and Crack Patterns of Broken Glass
}

\author{
Richard C. Bradt
}

Submitted: 22 December 2010/Published online: 26 January 2011

(C) ASM International 2011

\begin{abstract}
The topographical features which appear on the fracture surfaces of broken glass objects and the resulting crack patterns which develop are Nature's documentation of the fracture event. They are considered after a brief discussion of glass strength. Strength is central to the fracture surface features for it determines the strain energy release rate and the dynamics of crack extension. The surface features known as the mirror, the mist, and the hackle are illustrated and addressed through the principles of fracture mechanics and associated energy criteria. Quantitative aspects of the fracture process such as the stress level at fracture for a glass object are directly related to the size of the fracture mirror. The concept of a fracture mirror constant is related to the strength. Formation of the mist and hackle surface regions are also fundamentally addressed, as is crack branching. Distinctive crack patterns that evolve during fracture, that is the traces of the cracks intersecting the glass free surfaces, are described. Dicing fragmentation of high-strength tempered glass and the long sword-like shards of low-strength annealed glass fracture are contrasted through their strain energies. Characteristic cracking patterns are reviewed for several common glass fractures including those for pressure breaks, both bottle explosions and flat glass window failures from wind pressure whose basic similarities are described. The patterns of crack branching or forking, the branching angles and the crack length prior to forking, are also discussed. Other
\end{abstract}

This article is an invited paper selected from presentations at MS\&T 2009, held October 25-29, 2009 in Pittsburgh, Pennsylvania, and has been expanded from the original presentation.

R. C. Bradt $(\square)$

The University of Alabama, Tuscaloosa, AL 35487-0202, USA

e-mail: Rcbradt@eng.ua.edu glass crack patterns such as those from impact and thermal stress are also considered.

Keywords Glass fracture - Fracture mechanics · Mirror · Mist · Hackle - Crack branching · Forking

\section{Introduction}

The fracture surface topography and the crack patterns that develop when any glass object breaks are of interest for many reasons. Paramount, from an academic point of view, is the continuing quest for a greater fundamental understanding of glass strength. It also includes understanding how and why cracks in glass extend or grow in the myriad of ways that they do. From a more practical perspective, there is the assignment of responsibility for glass failures in litigation when there are personal injuries. Eyewitness accounts are not always reliable as the anxiety of the moment may create confusion among observers. However, the topographical surface features of the broken glass and the resulting crack patterns of the reconstructed glass object will accurately, objectively, and faithfully document the history of the glass fracture event.

Glass usually appears to fracture instantly and dramatically, as when a thrown rock or other projectile hits a glass window. When glass containers break they often seem to violently explode in all directions. However, glass fracture events consist of the extensions of individual cracks that rupture a single atomic bond at a time. The crack extension, even though only breaking one bond at a time, typically occurs so fast during a glass fracture event that it appears to be instantaneous to the observers.

Glass is not highly resistant to fracture. Its fracture toughness, $K_{\mathrm{IC}}$ value, is only $\sim 1 \mathrm{MPa} \cdot \mathrm{m}^{1 / 2}$. Glass is brittle, 
considerably less tough than even the most brittle of metals, such as the cast irons. This very low fracture toughness makes glass highly susceptible to various forms of surface damage. Glass is sensitive to the creation of surface flaws which are the precursors to most glass failures. The consequence of this high level of surface sensitivity is that glass objects readily develop surface flaws and then can be easily broken under a wide variety of conditions and at different states of stress.

Fracture toughness values of glass are comparable to those of many polymers, or plastics. One consequence is the development of similar topographical features on the fracture surfaces of both polymers and glasses. For example, the fracture mirror of glass is called the smooth region in polymers. Fracture also creates similar crack patterns in both glasses and polymers. However, because the elastic moduli of polymers are much lower than inorganic silicate glasses, the terminal crack velocities for polymers are lower.

In spite of its low value of fracture toughness, fresh or pristine glass with a flaw free surface can be very very strong. Pristine glass fibers are among the strongest of all known materials. To generalize the strengths of inorganic glasses one might paraphrase Charles Dickens' opening lines from his classic, A Tale of Two Cities, "It was the best of times, it was the worst of times." The glass strength analogy ala Dickens is that: "Glass can be one of the strongest of all materials with strengths $>10 \mathrm{GPa}$ for pristine fibers, and one of the weakest of all materials with strengths $<20 \mathrm{MPa}$ for weathered windows and glass objects that have been subjected to surface damage." The analogy and paraphrase of the opening lines from A Tale of Two Cities is most appropriate to describe the strength of glass under the many different circumstances under which glass failures occur.

\section{The Strength of Glass as it Affects Glass Fracture}

The strength of a glass object has a profound effect on the resulting fracture features. The level of the fracture stress directly affects the crack patterns which develop when propagating cracks intersect the surface (traces) of a glass object. This is because it is the strength, the fracture stress, that determines the level of stored elastic strain energy in the glass. It is the stored elastic strain energy at fracture that drives the crack extension, the crack growth. That energy is proportional to the square of the strength of the glass, $\sigma_{\mathrm{f}}^{2}$. For example, in a pristine glass fiber where $\sigma_{\mathrm{f}}^{2} \sim 10 \mathrm{GPa}^{2} \sim 10^{20} \mathrm{~Pa}^{2}$, the elastic strain energy per unit volume is far greater than that for a weathered window glass where $\sigma_{\mathrm{f}}^{2} \sim 20 \mathrm{MPa}^{2} \sim 4 \times 10^{14} \mathrm{~Pa}^{2}$. This is a factor of nearly $10^{6}$, a million times different for the stored elastic strain energy of these two extremes of glass strengths. For precisely that reason, discussion of the fractography of glass and the characteristic crack patterns that form during the extension of a crack, or multiple cracks in glass, must begin with consideration of the strength of glass.

However, prior to addressing strength, it is important to note that additional forms of energy in addition to the stored elastic strain energy, may also contribute to the fracture and fragmentation of glass objects. When that additional energy is comparable in magnitude to the stored elastic strain energy, then it must be considered for any total energy balance. Two examples are when a glass object is dropped (the potential energy from the height of drop) or impacted by a projectile (the kinetic energy of the projectile). It has also been noted and discussed by Yoffe that for any dynamic analysis of glass fracture, the kinetic energy associated with crack extension must be considered. This should not be surprising for kinetic energy is associated with velocity and the terminal crack velocity in a soda-lime-silicate window glass is substantial, $\sim 1,500 \mathrm{~m} /$ s. Unfortunately, any all inclusive energy balance for the dynamic fracture of glass is a challenging problem. However, energy balances have been attempted by several researchers and those efforts have lead to an increased understanding of several of the dynamic aspects of glass fracture.

Inorganic silicate glasses are the quintessential, brittle, linear elastic materials as has been demonstrated by Shinkai et al. For that reason, glasses are ideal for the application of linear elastic fracture mechanics, LEFM. Glasses have low values of fracture toughness, only $\sim 1 K_{\mathrm{IC}}$, and they also exhibit flat $R$-curves for their crack growth resistance. Inorganic silicate glasses fractures at room temperature are without significant "flow" in the vicinity of their crack tips, although contrarians continue to argue that point. Glasses are believed by most fracture researchers to be $100 \%$ brittle! For the above reasons, it is appropriate to address the strength and fracture of glass, $\sigma_{\mathrm{f}}$, from the LEFM perspective. It is not a problem even if there is a "smidgeon" of crack tip flow in glass. LEFM has proven to be applicable to brittle metals that exhibit plasticity through dislocation generation and motion in the vicinity of their crack tips during their fracture.

Application of the energy-based principles of LEFM for crack growth parameters also enables a fundamental approach to further the understanding of the development of the crack patterns that form in broken glass objects. These characteristics include the traces of the propagating cracks intersecting the surface when bifurcation (also known as branching or forking) occurs. However, one must also be appraised that the application of fracture mechanics principles, LEFM, has not completely clarified, nor explained all of the possible aspects of glass fracture, yet. It 
is a formidable task indeed to understand glass fracture in its entirety and the science has a long way to go to complete that task. For example, Yoffe described the kinetic energy of cracks in 1951, but these energies have never been fully incorporated into a closed form energy balance for glass fracture.

The classical Griffith Equation for fracture in LEFM form may be directly applied to specify the strength or the fracture stress, $\sigma_{\mathrm{f}}$, of glass. That equation is:

$\sigma_{\mathrm{f}}=\sqrt{ } 2 E \gamma / \pi C, \quad$ or $\sigma_{\mathrm{f}}=K_{\mathrm{IC}} Y C^{-1 / 2}$,

where the term $\gamma$ is the fracture surface energy of the glass and $C$ is the flaw size at the instant of fracture in the original Griffith energy balance. In LEFM, $K_{\text {IC }}$ is the fracture toughness and the $Y$ is a constant relating to the flaw geometry. The $Y$ is $\pi^{-1 / 2}$ for the original Griffith center crack geometry. From the general form of this equation, namely that the strength, $\sigma_{\mathrm{f}}$, is proportional to the inverse square root of the critical flaw size, $C^{-1 / 2}$, Kurkjian has presented a comprehensive strength/flaw size diagram that illustrates typical values of practical glass strengths and their flaw sizes at fracture. The Kurkjian diagram in Fig. 1 is an excellent summary of glass strengths in many everyday applications. This type of diagram may be extended to represent other glass structures, not just the familiar inorganic silicates.

The range of practical strengths for glass, as paraphrased from Dickens' opening lines, are summarized in the Kurkjian diagram. In that regard, glass is quite remarkable among all materials. This wide range of strengths is indicative of the extensive range of flaw sizes that may exist, or can be introduced into glass. Surface flaws are easily created during handling because glass has such a low fracture toughness. In addition, those flaws which are

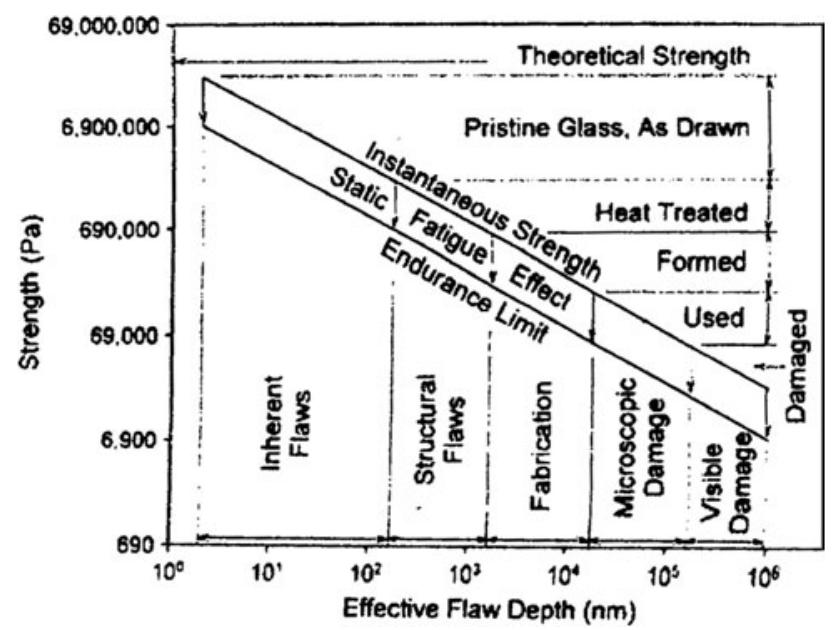

Fig. 1 The Kurkjian diagram for the strength variation with flaw size for many different glasses and common glass objects present also experience fatigue-induced growth, as crack length increases during the stressing or loading of a glass object. This is also illustrated on the Kurkjian diagram. It is important to understand that the flaws which are present in glass actually become larger and more severe during stressing glass objects, prior to their fracture. This fatigue phenomenon occurs during the laboratory strength testing of geometrically prepared glass strength samples and also during the failure of practical glass objects with complicated shapes that are loaded in complex states of stress in their applications.

The fundamentals of the crack growth which occurs during loading for different chemistries of glass has been studied by Wiederhorn. One of Wiederhorn's experimental $K_{\mathrm{I}}-V$ diagrams of crack velocity variation with stress intensity is reproduced in Fig. 2 for four common glasses. Strengths become lower during stressing because the flaws which are present increase in severity during loading. This is known as subcritical crack growth or fatigue, a form of stress corrosion. At room temperature in air, this stress corrosion process has been attributed to a chemical reaction of the stressed crack tip of the glass with the moisture, $\mathrm{H}_{2} \mathrm{O}$, in the atmosphere, the relative humidity. The obvious consequence of this phenomenon is that glass is stronger at higher stressing rates. Simply explained, this is because the flaws have less time to grow during the stressing period prior to achieving the critical condition for fracture when $K_{\mathrm{I}}$ reaches $K_{\mathrm{IC}}$ at the most severe flaw.

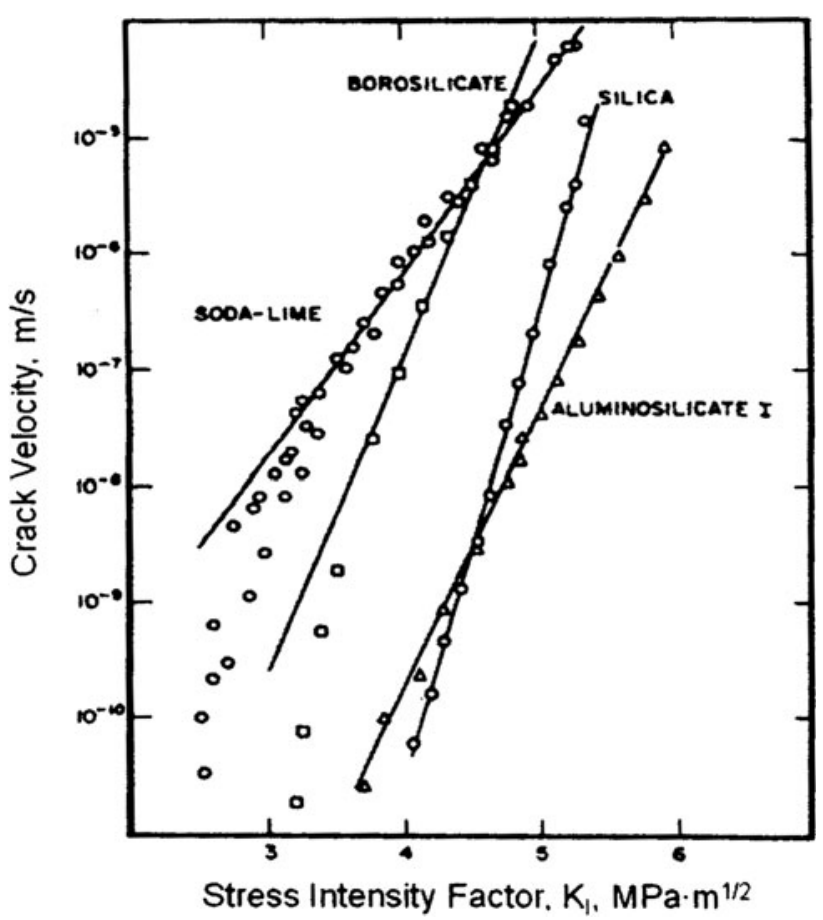

Fig. 2 Wiederhorn's general $K_{\mathrm{I}}-V$ diagram for subcritical crack growth in several familiar inorganic silicate glasses 
Environmentally enhanced fracture or subcritical crack growth can be reduced by changes in the moisture of the environment surrounding the glass surface flaws as has been noted by Frieman et al. It can be eliminated by preventing moisture or humid air from contacting the stressed crack tips at a glass surface, or by testing the glass under liquid nitrogen where moisture is kinetically frozen out of the stress corrosion process. Testing in water-free liquids such as some organics can also eliminate the phenomenon, if those liquids are truly water free. When this subcritical crack growth is eliminated, then the glass will be much stronger because the flaws have no opportunity to increase in length during stressing prior to fracture.

This stress corrosion fatigue is significant in determining the practical strength of glass, that is the stress level at which glass fractures. Results of Chandan et al. are presented in Fig. 3 and illustrate the effect of the stressing rate on the room temperature bend strengths of a soda-limesilica float glass for a wide range of loading (stressing) rates. The slower loading rates in the figure were measured with a conventional mechanical testing machine and the higher testing rates by instrumented impact tests on similar specimens. In the Chandan plot, the glass strengths at different stressing rates are compared with the strength in liquid nitrogen indicated by the horizontal dashed line across the top of the figure. It is evident that a wide range of strengths that are much lower than the inert or liquid nitrogen strength may occur. Glass strength is highly sensitive to the stressing (loading) rate. Unfortunately, the stressing rate has not often been reported in the archival literature of glass strength measurements.

The strength of glass, its fracture stress, $\sigma_{\mathrm{f}}=\sigma_{\text {fracture }}$, is usually just the maximum stress which is applied to the

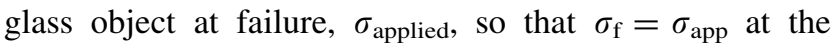
instant of fracture. However, an important exception occurs when a residual stress, $\sigma_{\text {res, }}$ is present as discussed by
Redner et al. The residual stress acting on a crack in glass is additive to the applied stress. In the cases of thermally or chemically tempered and heat-strengthened glasses, the fracture stress is the applied stress plus the residual stress: $\sigma_{\mathrm{f}}=\left(\sigma_{\mathrm{app}}+\sigma_{\mathrm{res}}\right)$.

Engineers are familiar with strengthened or tempered glasses whose surface is put into a state of compression, either by thermal processing or through a form of ion exchange. Tempered structural glasses can have considerably enhanced strengths. The process can increase the strength by a factor of three, or more as reported by Redner et al.

Tempering of glass creates a high level of surface compressive residual stress. That compression must first be overcome before cracks can extend and fracture occur. For that situation, the Griffith Equation expressing $K_{\mathrm{IC}}$ as the failure criterion requires a slight modification that includes the residual stress. It then becomes:

$K_{\mathrm{IC}}=\left(\sigma_{\mathrm{app}}+\sigma_{\mathrm{res}}\right) Y^{-1} C^{1 / 2}$,

where the residual stress, $\sigma_{\text {res, }}$ which is compressive and negative, is added to the positive applied stress, $\sigma_{\text {app }}$, as indicated in Eq. 2. Fracture of tempered glass requires a much larger applied stress, $\sigma_{\text {app }}$, to reach the critical level of fracture toughness, $K_{\mathrm{IC}}$, at the crack tip, for the compressive residual stress is subtracted from the applied stress.

An important consequence is that when glass is strengthened by creating a large compressive residual stress such as by tempering, then the stored elastic strain energy at fracture increases significantly to levels much greater than that those of annealed, residual stress-free glass. Tempered glass has a far greater propensity for multiple cracking during fracture. This is because the strain energy release rate is determined by $\sigma_{\mathrm{f}}^{2}$, and for a tempered
Fig. 3 Chandan's diagram of the stressing rate effect on strength for a soda-lime-silica float glass

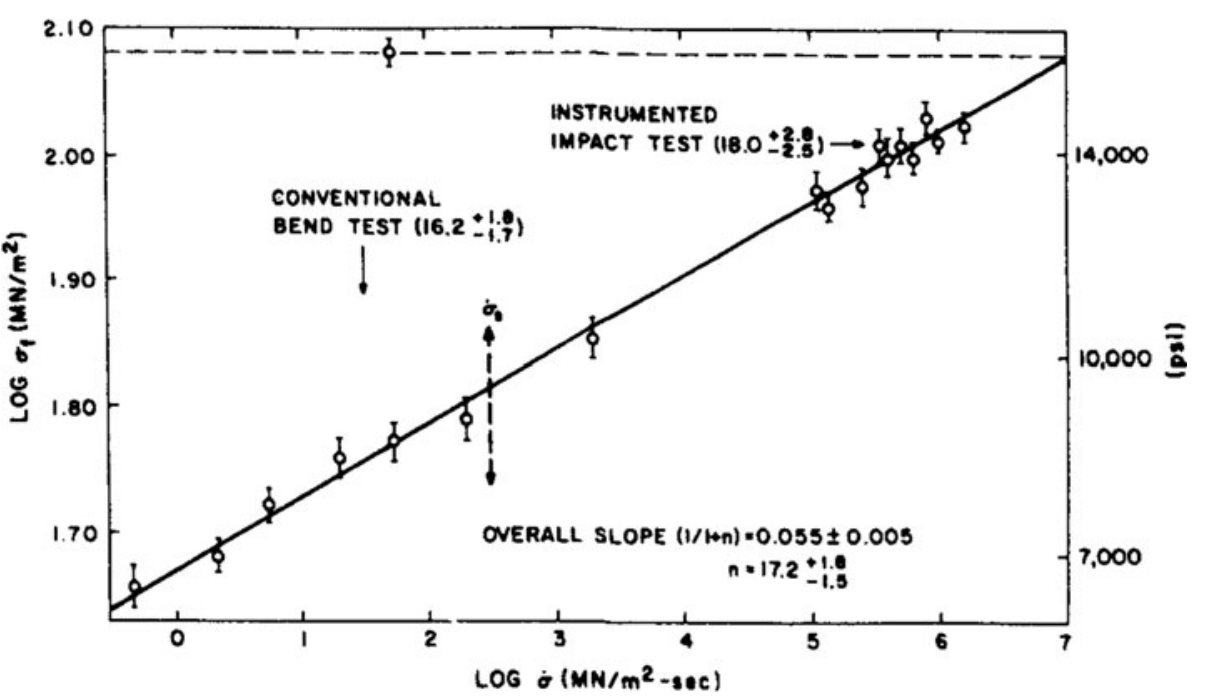


glass, $\sigma_{\mathrm{f}}^{2}=\left(\sigma_{\text {app }}+\sigma_{\text {res }}\right)^{2}$. For example, if the glass strength, $\sigma_{\mathrm{f}}$, is enhanced by a factor of three during tempering, then the elastic strain energy release is increased by about an order of magnitude and dramatically affects the cracking patterns.

The extensive fragmentation that occurs during the failure process of highly tempered glass is known as dicing. Figure 4 schematically illustrates the cracking patterns of annealed and tempered glass panels after McMaster et al. A far greater extent of fragmentation into small equiaxed pieces occurs for the temper strengthened glass panel. This is because the stored elastic strain energy at fracture is so much greater when a residual stress is present. The result is that much greater fracture surface area is created during the fracture process resulting in small equiaxed fragments as opposed to the large "lance-like" shards that develop during the fracture of annealed glass objects. Warren has extensively studied this dicing fragmentation process in thermally tempered glass plate. His work is recommended as the basis for further study of the phenomenon.

From the equations and discussions presented above, it is evident that there are at least three approaches to increase the practical strength of glass. One is to reduce the flaw size as expressed in the basic Griffith Equation and also illustrated on the Kurkjian diagram. Pristine glasses are strong because their intrinsic flaws are very small. It is also possible to increase glass strength by increasing the fracture toughness, that is to increase the $K_{\mathrm{IC}}$ value by chemical composition alterations. Unfortunately, the toughness approach by itself does not appear to be capable of yielding substantial strength increases, for significant $K_{\text {IC }}$ increases do not appear to be possible for most inorganic glasses. The third technique is to put the surface of the glass into a state of compression with an internal residual compressive stress. Tempering is currently a common practice for strengthening glass in many practical applications. It can be achieved by the appropriate thermal treatment or by chemical ion exchange processes at the glass surface.

There is yet a fourth approach that is not directly revealed by the basic Griffith Equation, but is evident from the Wiederhorn $K_{\mathrm{I}}-V$ diagram. It is to reduce the rate of the fatigue or subcritical crack growth during stressing of the glass to failure. One can either chemically modify the glass composition to reduce the rate of subcritical crack growth, or one can coat the glass surface or otherwise treat the glass to prevent environmental moisture from reaching the crack tips when the glass is stressed. This is simply inhibiting the stress corrosion that occurs at the crack tip, which was shown by Chandan et al. to significantly reduce glass strength. All four of these approaches and other technically related processes remain active areas of research in glass science.

Recently, Corning has released and promoted a glass product which they have termed to be Gorilla Glass. It is
Fig. 4 Crack patterns of annealed and a tempered glass plates after McMaster et al. Note the extensive fragmentation of the latter
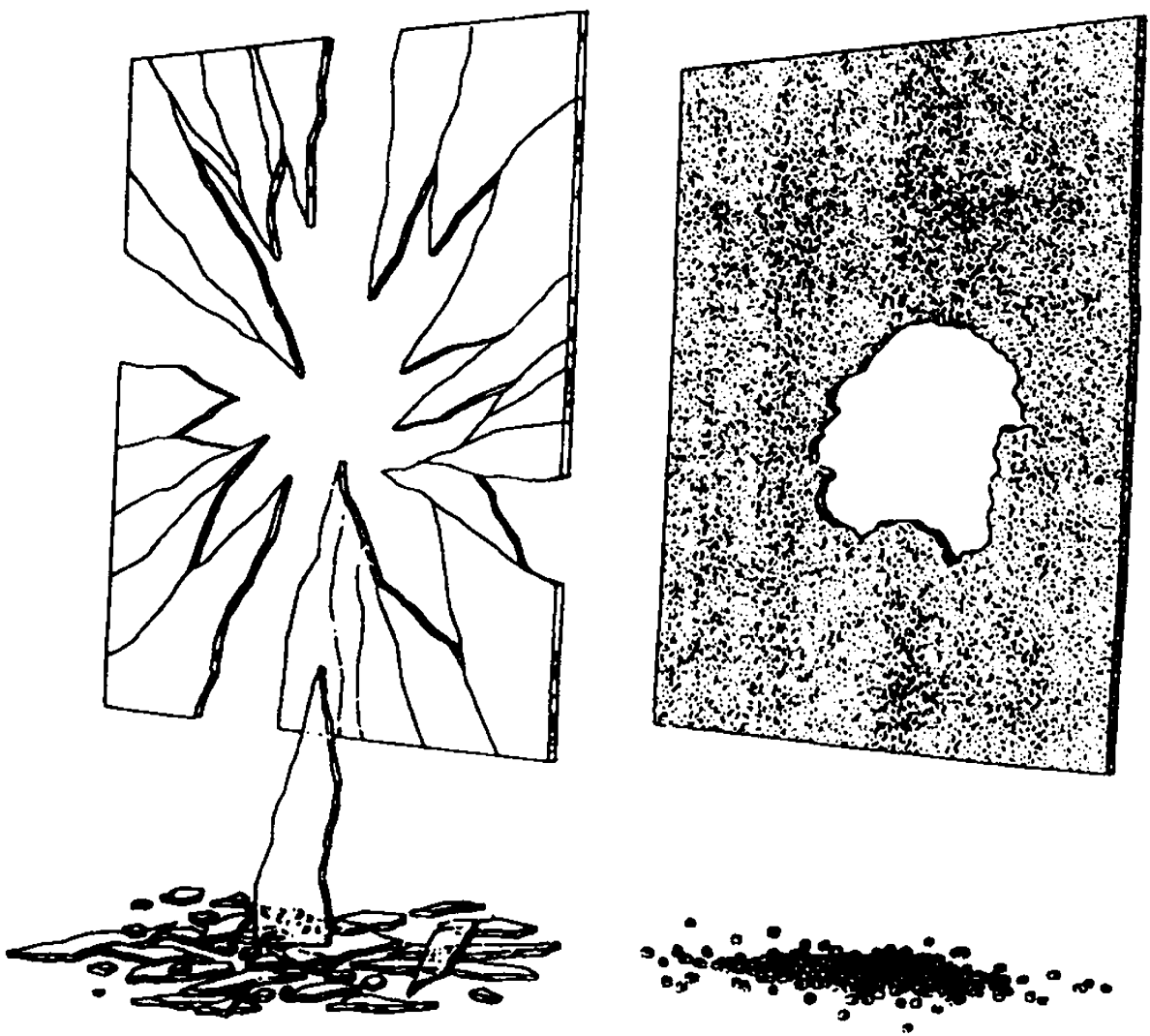
a strong, crack resistant glass that is suitable for many modern transparent electronic faceplates. Gorilla Glass appears to incorporate several of the above concepts. It is an alkali-aluminosilicate sheet glass, which when compared with soda-lime-silicate glass has a higher elastic modulus, a higher the fracture toughness, and a higher hardness. It therefore has a greater resistance to surface contact damage than does a soda-lime-silica. In addition, the glass is chemically tempered, probably by the exchange of $\mathrm{K}^{+1}$ for $\mathrm{Na}^{+1}$ to create a surface compressive stress. In Fig. 2, the aluminosilicate also appears to be less susceptible to slow crack growth. Several of the strengthening processes for Gorilla Glass are those defined by the Griffith Equation. They appear to combine synergistically to increase the practical strength of Gorilla Glass.

\section{Spatial Coordinates for Describing Fracture Surface Topography and Crack Patterns}

The fracture surface topography and the evolving crack patterns, or crack traces that develop in glass can be described with reference to a coordinate system that is superimposed upon a familiar fracture mechanics test specimen. Those coordinates can then be translated to other glass objects. This enables the specification of two complementary viewing planes that are critically important for the description and understanding of the glass fracture process. The double cantilever beam (DCB) specimen in Fig. 5 illustrates an $x-y-z$ coordinate system superimposed upon its geometry. In this article, the fracture surface for describing the fracture topography will be the $x-y$ plane. The $z$-direction is normal to this plane. The $z$-direction is the orientation from which most fractography is accomplished viewing the fracture surface. Observation from the $z$-direction reveals the history of the fracture event as the primary crack extends in the $y$-direction and forms the fracture features on the $x-y$ surface.

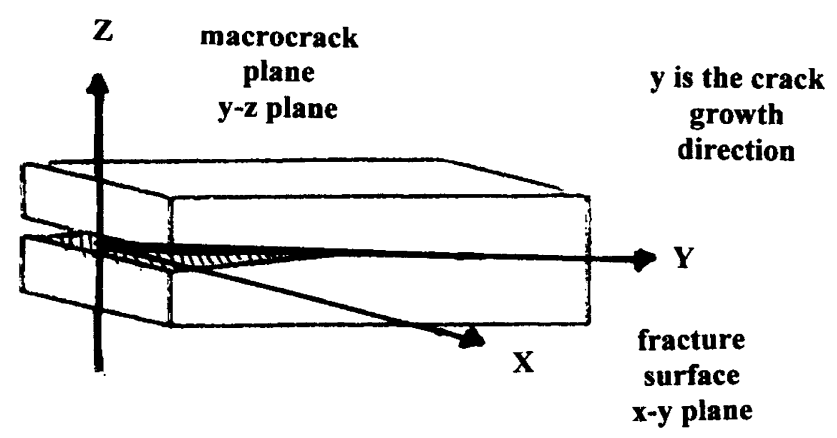

Fig. 5 A coordinate system on a double cantilever beam fracture specimen to describe fracture surfaces and crack patterns
The crack pattern or surface intersection trace that develops during crack growth or extension is then observed when the extending crack intersects the $y-z$ plane which traverses the center of the specimen in Fig. 5, but is also the surface plane of the near outside surface of the specimen. This crack pattern is the trace of the crack intersection with the $y-z$ plane surface of the DCB specimen. Although the crack pattern is observed on the side surface of this specimen, crack traces represent intersections of extending cracks with any free surface of a glass object or artifact. For example, when a crack pattern develops, such as those observed during the fracture of a flat glass window, a bottle or an auto windshield, it is the DCB $y-z$ plane orientation surface of that glass artifact that reveals the pattern or trace of the extending crack.

\section{The Fracture Surface}

The fracture surface, the $x-y$ plane in Fig. 5, is usually the first to be viewed by a glass fractographer or other observer. The perspective from this view allows the observation of the chronological development of Nature's documentation of the fracture event. It directly records the history of the crack growth process from the crack initiation in the form of several important topographical features that a growing crack creates as it extends. These will be addressed in the sequence of their occurrence.

The point of crack initiation in a glass fracture is known as the fracture origin. It is a critically important feature to identify during the description of any glass fracture event for it is central to the development of the fracture surface topography. Features on the $x-y$ fracture plane make it possible to precisely locate and identify the origin of the fracture. At the fracture origin, one can often identify the specific flaw that was responsible for the failure. The arrows on the fracture mirror surface in Fig. 6 identify such a flaw, an inclusion within the optical fiber. The location and the orientation of the flaw may provide additional information about the state of stress of the object at fracture.

Once a crack initiates in any glass object, there are distinctive surface features which develop during the crack extension from its origin. The optical fiber fracture in Fig. 6 illustrates those features: (i) a smooth fracture mirror, (ii) the hazy stippled mist region, and (iii) the ridges and valleys of the rough hackle lines. The three regions develop in that sequence as the primary crack extends from the origin in $360^{\circ}$. These fracture surface features are precursors to the eventual bifurcation or forking of the primary crack into two secondary cracks. Attention was drawn to the importance of the mirror, the mist, and the hackle regions by Johnson and Holloway in the 1960s, 


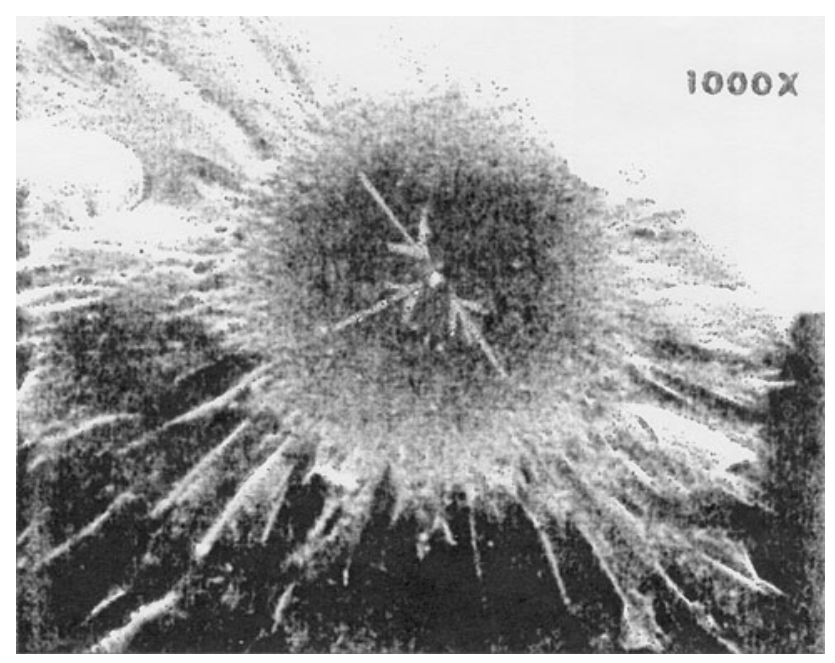

Fig. 6 The fracture origin, mirror region, mist, and hackle for a highstrength optical fiber broken in tension after Chandan et al.

although these three regions had been previously observed and reported by other researchers. Those three regions have been extensively discussed ever since, but the criteria and the mechanisms of their formation remain controversial after nearly half of a century.

Descriptively, the fracture origin, the point of crack initiation, is surrounded by a smooth flat circular region. Because of that smoothness, in glass fractography it is known as the fracture mirror, although in the fractography of polymers it is simply called the smooth region. The smooth flat fracture mirror region is indicative of a stable planar form of crack growth away from the origin. The fracture mirror in Fig. 6 of the high-strength optical fiber illustrates a complete $360^{\circ}$ development of the mirror region from an internal fracture origin. The internal origin is identified by the arrows drawn within the mirror by the extension of hackle lines. This form of fracture initiation from an internal defect is unusual for glass, as glass objects usually fail from surface defects.

In addition to the fracture mirror region, also evident in Fig. 6 is the narrow band of mist concentrically surrounding the mirror and the origin. Beyond the mist band, still further from the fracture origin, the ridges and the valleys of the hackle appear. When ridges of the hackle are extended back through the mist band and the mirror region, they focus to the fracture origin. The arrows drawn on Fig. 6 are extensions of hackle lines toward the origin. In Fig. 6, the fracture origin is clearly visible as the light spot of an inclusion in the center of the complete, fully circular, $360^{\circ}$ fracture mirror.

There is a wealth of experimental data reported for the mirror/mist/hackle surface features of glass fractures, but there is truly a paucity of fundamental understanding as to their precise formation process. Quantitative criteria have not been determined for any of the transitions from one

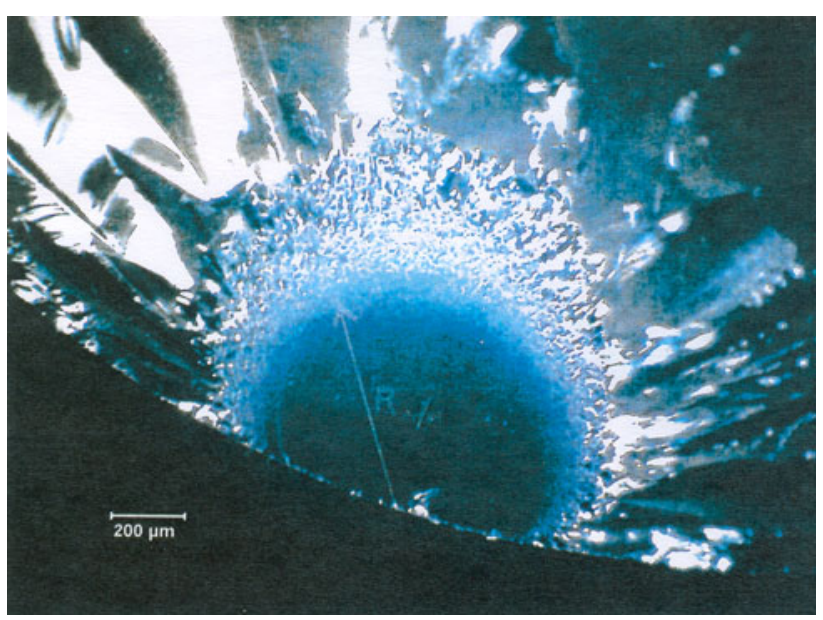

Fig. 7 The mirror-mist-hackle sequence on a low-strength cylindrical glass rod broken in flexure after Quinn

region to the next proceeding away from the origin. This lack of basic criteria will be addressed after illustrating and describing these three topographical features for a surface fracture origin of a bending failure for it is slightly different than that of the internal fracture of the optical fiber origin in Fig. 6.

Figure 7 depicts the fracture surface of a low-strength glass rod that was broken in bending. This specimen failed from a surface flaw. The fracture surfaces of Figs. 6 and 7 are similar, but failure initiation from the surface flaw only allows a partial development, usually $\sim 180^{\circ}$ of the total fracture mirror. One can usually observe these fracture mirrors for most glass fractures with a low-magnification eyepiece, or a stereo microscope. Sometimes a mirror can even be seen with the naked eye, particularly for lowstrength fractures that have very large, well-defined fracture mirrors.

As shown in Fig. 7, it is evident that as one moves in a radial direction away from the fracture origin, the smooth mirror regions gradually degenerates into a narrow, slightly rougher or stippled band about the smooth flat mirror. This area of increasing roughness is known as the mist region. The mist is the onset of dynamic instability of the stable planar crack to deviate from the "perfectly" flat mirror surface. This region is known as the mist for it appears as though a light mist has condensed on the smooth mirror surface. Mist regions are clearly visible surrounding the smooth mirror regions in both Figs. 6 and 7. Although the mist region initiates with only a few minor bumps or dimples on the flat mirror surface, it increases in roughness in a radial direction away from the fracture origin toward the hackle beginning. This has been documented by Ball et al. using stylus profilometry.

On proceeding through the mist, the extending crack experiences increasingly greater dynamic instability. That 
instability causes the transition into a third fracture surface feature that is known as the hackle. The hackle region is a rough surface of angled ridges and valleys that appear to have been "hacked" into the glass fracture surface with an axe, or perhaps a machete. Hackle lines always radiate away from the fracture origin, so that when the hackle lines are extended as straight lines back through the mist region and across the mirror surface, their extensions intersect at the origin, the point of fracture initiation. This was shown in Fig. 6 with the white line arrows that follow the hackle ridges in the micrograph to the origin in the fiber. This simple method of hackle ridge extension precisely locates the fracture origin. Hackle ridge extension is the accepted technique to locate and identify fracture origins in all types of broken glass objects. The method is applicable to many structural ceramics and to polymers as well.

In both Figs. 6 and 7, but especially in Fig. 7, it is possible to clearly observe the transition from the smooth mirror to the stippled mist region as the planar crack growth stability degenerates in a radial direction away from the origin. That instability first creates the increasingly rougher, dimpled features of the mist region and then eventually transitions into the much rougher ridges and valleys of the hackle. It is beyond the hackle ridges and valleys, much further from the fracture origin, that forking or bifurcation of the primary crack occurs to form two secondary crack branches.

The three fracture surface regions occur concentrically, $360^{\circ}$ about the origin in the pure tensile fracture of the optical fiber. However, for surface flaws in bending they are present for only $\sim 180^{\circ}$, as the other half of the mist/ mirror/hackle sequence would have been outside of the specimen. This is clearly illustrated in Fig. 7 for the mist/ mirror/hackle regions of a low-strength cylindrical glass rod broken in flexure. The region appearances are slightly different than for the optical fiber broken in tension. Instead of propagating into a uniform tensile stress during fracture, the crack in the bending specimen extends into a region of decreasing tensile stress as the crack proceeds toward the neutral axis of the specimen in the state of flexure or bending. In Fig. 7, one can observe that the mirror/mist boundary appears to be slight closer to the fracture origin at the specimen surface than toward the interior along a mirror diameter from the origin toward the rod center. This is consistent with the locally higher stored elastic strain energy in the more highly stressed surface regions at the instant of fracture initiation. There has long been controversy over the proper measurement technique to determine the fracture mirror radius. This dilemma is extensively discussed by Quinn in his handbook.

From the work of Ball et al. and in Figs. 6 and 7, it is evident that the mist region is a rougher surface than the mirror region. Also, apparent is that the roughness of the mist gradually increases as one proceeds through the narrow concentric band of mist into the angled hackle ridges and valleys. Although the mirror/mist boundary appears visually quite distinct and well defined, the mist transition into hackle is much less definitive. Although investigators often report a mist/hackle radius as well as a mirror/mist radius, it is a challenge to precisely identify a well-defined mist/hackle transition boundary. This is because at some locations along that boundary, the mist seems to penetrate deeply into the hackle and at others it does not. Although a mist/hackle boundary appears to be evident when viewing a glass fracture surface, it is not quite so precisely defined as the mirror/mist boundary.

As previously noted, the hackle region appears as though the surface was "hacked" with an axe or machete during its formation. It consists of deep angled ridges and valleys that extend radially away from the crack initiation point. In his text, Hull describes the hackle as facets or steps that are aligned parallel to the crack propagation direction. It is a perfect description. This radiating nature of the hackle allows one to precisely locate the fracture origin. The geometry of the hackle, that is the angles of the hackle surfaces relative to the mirror plane are suggestive of nonMode I fracture.

The evolution of the three mirror/mist/hackle region surface topographies merit brief summaries prior to proceeding. Only then is it appropriate to quantify these fracture surface topographies and address further crack growth beyond the hackle to energetically explain crack forking or branching. It follows that:

(i) As one progresses through the mirror/mist/hackle sequence of regions that surround the fracture origin, the fracture surface roughness increases.

(ii) The boundaries between the regions are not sharp discontinuities, but are progressive, evolutionary transitions. This gradual nature is most apparent for the interpenetrating mist to hackle transition.

(iii) The three regions are associated with increases in the crack length. They probably relate to the stress intensity factor, $K_{\mathrm{I}}$, in a dynamic sense.

(iv) These three regions are sequential precursors to macroscopic crack branching which occurs beyond the mist/hackle transition.

From their characteristics, it is possible to quantitatively describe these three regions in terms of their formation and their transitions and to relate those quantities to the glass fracture event. However, before doing just that, it is necessary to note that in addition to the mirror/mist/hackle sequence, other features, including Wallner lines and dwell marks are also frequently present on glass fracture surfaces. These are highly beneficial to identify the crack growth direction, especially when multiple intersecting cracks 
occur. However, the following will be limited to the three important points: (i) determining the fracture origin, (ii) identifying the crack path or growth direction, and (iii) estimating the stress level at fracture. Obviously, these three items are not independent of one another and are essential to the basic understanding of any glass fracture event.

\section{The Crack Velocity in the Mirror/Mist/Hackle Regions}

A glass fracture initiates when the stress intensity at the most severe crack tip is $K_{\mathrm{IC}}$, the fracture toughness of the glass. The crack velocity at $K_{\mathrm{IC}}$ is $\sim 0.1 \mathrm{~m} / \mathrm{s}$. However, once a crack initiates, it accelerates rapidly through the mirror region. That acceleration occurs at increasing $K_{\mathrm{I}}$ values and under the driving force of a continually increasing strain energy release rate. The energy release rate increases linearly with crack length, $C$. For that reason, as the crack grows, there is increasingly more energy available for continually accelerating the crack to ever higher velocities until the terminal velocity is achieved. That terminal velocity is related to the speed of sound. It is $\sim 10^{3} \mathrm{~m} / \mathrm{s}$.

The flat, exceedingly smooth surface character of the fracture mirror region is characteristic of a stable planar crack growth. It is this planar stability that enables the extending crack to create the almost perfectly flat smooth mirror surface. However, as the crack is extending and accelerating to reach its terminal velocity, this planar stability becomes a fleeting phenomenon as local dynamic instabilities develop as mist droplets as the accelerating crack approaches its terminal velocity.
Near to the boundary of the mirror region, the crack front experiences the onset of dynamic instability with development of the mist features. Richter notes that for a soda-lime-silicate glass, the mist region forms as the terminal crack velocity of $\sim 10^{3} \mathrm{~m} / \mathrm{s}$ is achieved. After the mist, the fracture surface then rapidly degenerates into the much rougher hackle region while at the crack terminal velocity. According to Richter, Fig. 8, the hackle region develops at the terminal velocity. That terminal crack velocity is $\sim 4$ orders of magnitude greater (faster) than the velocity at crack initiation, $K_{\text {IC }}$.

The mirror, mist, and hackle regions are depicted on Richter's experimental $K_{\mathrm{I}}-V$ diagram in Fig. 8. All three of the topographical regions, the mirror, the mist, and the hackle exist within the terminal crack velocity plateau of the $K_{\mathrm{I}}-V$ diagram. The fracture mirror region actually extends from velocities of $\sim 10^{-7}$ to $\sim 10^{3} \mathrm{~m} / \mathrm{s}$ according to Richter. Only after the crack reaches the terminal velocity plateau at $\sim 10^{3} \mathrm{~m} / \mathrm{s}$ does the mirror transition into the mist, forming the mirror/mist boundary at $R_{\mathrm{m} / \mathrm{m}}$. While extending at the terminal velocity, the crack then forms the hackle region, the last characteristic region prior to bifurcation or forking.

The criteria for the transitions of the mirror to the mist and the mist to the hackle regions are controversial. Several criteria have been suggested, including ones based on crack velocities, dynamic instabilities of the moving crack and specific values of the stress intensity factor. Note that Richter's Fig. 8 does not reveal any form of sharp discontinuity in either $V$ or in $K_{\mathrm{I}}$. The nucleation of small micro-cracks, possibly even voids just ahead of the advancing crack tip has been advocated as a physical mechanism for the changes from the smooth mirror surface
Fig. 8 A $K_{\mathrm{I}}-V$ diagram after Richter, depicting the locations of the mirror, the mist, and the hackle within the terminal crack velocity region

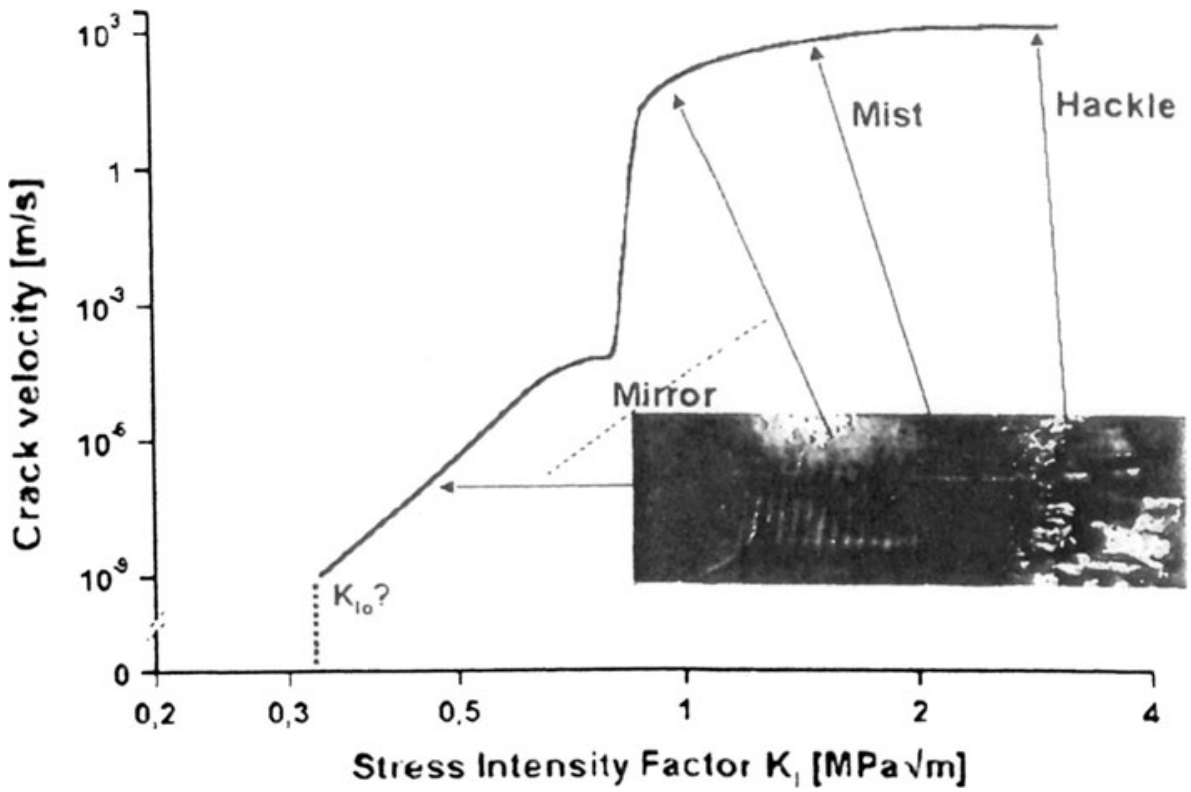


to the dimpled mist region and eventually to the very rough fracture surface of the hackle. The criteria for these transitions and their region formations is far from a settled issue. It merits future serious research.

Analytically describing these topographical transitions are very challenging dynamic fracture problems. It is not surprising that the fundamental criteria for these transitions remain controversial. One aspect is certain, however, as Richter has observed that the mist and hackle regions both develop after the crack has achieved the terminal velocity as shown on his $K_{\mathrm{I}}-V$ diagram. That velocity is $\sim 1,500 \mathrm{~m} / \mathrm{s}$ for a soda-lime-silicate glass. Because both the mirror/mist and the mist/hackle transitions occur at the same velocity, the terminal velocity for crack extension, and there are no discontinuities in the $K_{\mathrm{I}}-V$ plot at these transitions, a specific crack velocity criterion probably cannot be developed for these transitions.

Hull has suggested that the formations of the latter two regions, the mist and the hackle, are the result of progressive and increasingly frequent micro-crack branching just ahead of the primary crack tip. The mist "droplets" are perceived as precursors to crack branching and eventually lead to the hackle and the primary crack's bifurcation. Hull and others visualize the sequence as being developed through the formation of numerous localized micro-cracks in the high-stress field that exists ahead of the primary crack tip. These eventually coalesce. By analogy, others have visualized the formation of micro-voids ahead of the primary crack front. These mechanisms remain highly controversial.

However, Hull's concept of micro-branching for the mist is an excellent starting point for an energy analysis. Energetically, on a quasi-static basis, the minimum strain energy release rate for crack branching or bifurcation must be that $G>2 R=4 \gamma$, for only then is sufficient energy provided by the main crack to form the two secondary crack branches. However, in actuality, that condition is achieved well before the mirror to mist transition occurs. This indicates that quasi-static energy criteria are not fully adequate for specifying formation criteria for either the mirror/mist or for the mist/hackle transition boundaries. Latif et al. suggest that the excess strain energy that is released above the level of $2 R$ is utilized by the crack in the form of kinetic energy to increase its velocity. It must also be remembered that once the primary crack eventually bifurcates into two secondary cracks, then there must also be sufficient kinetic energy for the two new cracks, actually the entire crack system to continue propagating at the terminal velocity.

\section{The Failure Stress (Strength) at the Origin and the Mirror/Mist Boundary Radius}

Preston was one of the first to observe that when glass fails at higher strength levels, then the glass has smaller radius fracture mirrors. The radius of the circular mirror/mist boundary, $R_{\mathrm{m} / \mathrm{m}}$, as shown in Fig. 7 , is smaller for glass objects that are stronger. This is consistent with an energyrelated criterion for the mirror/mist transition as the higher stress contribution of a greater stored elastic strain energy to the mirror/mist transition hastens its formation. Figure 9 is a summary plot of many different strength measurements versus their fracture mirror radii for fused silica compiled by Michalske from varied sources. It is evident from this plot for fused silica, that the strength and the fracture mirror radius, $R_{\mathrm{m} / \mathrm{m}}$, are in fact related as:

$\sigma_{\mathrm{f}} R_{\mathrm{m} / \mathrm{m}}^{1 / 2}=A_{\mathrm{m} / \mathrm{m}}$.

The $A_{\mathrm{m} / \mathrm{m}}$ parameter is known as the fracture mirror constant. Over a wide range of strengths for many different glasses
Fig. 9 A strength versus fracture mirror radius plot after Michalske

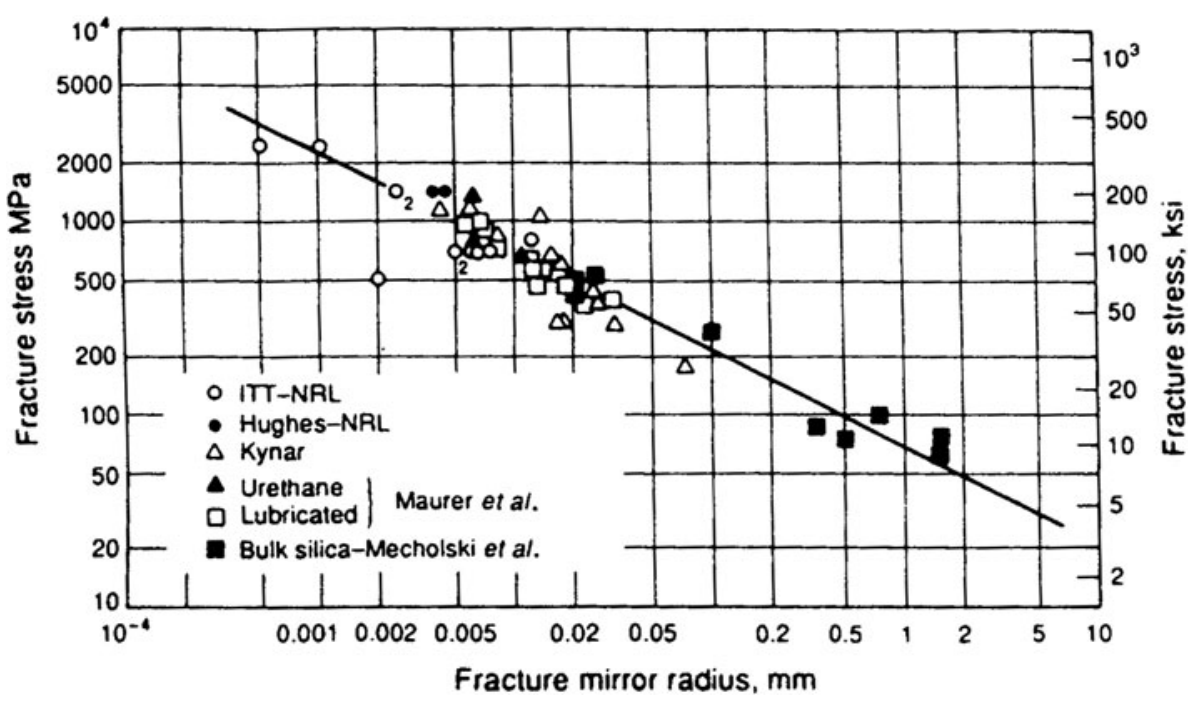


there is agreement with the above equation. For fused silica the mirror constant is $\sim 2.22 \mathrm{MPa} \cdot \mathrm{m}^{1 / 2}$. Although this is no more than a summary of empirical observations, the consistency of those observations is quite good.

It is further instructive if both sides of Eq. 4 are squared, even though the mirror constant is not usually viewed this way. By squaring the terms it illustrates that the fracture mirror radius, $R_{\mathrm{m} / \mathrm{m}}$, is inversely proportional to the square of the strength, $\sigma_{\mathrm{f}}^{2}$. Researchers, including Chandan et al. and Mecholsky et al. have independently shown that the mirror constant, $A_{\mathrm{m} / \mathrm{m}}$, is proportional to the glass elastic modulus for inorganic silicate glasses. Therefore, Eq. 4 can be rewritten to include the elastic modulus of the glass in the general form:

$R_{\mathrm{m} / \mathrm{m}}=B_{\mathrm{m} / \mathrm{m}} E / \sigma_{\mathrm{f}}^{2}=B_{\mathrm{m} / \mathrm{m}} / 1 / 2\left(\sigma_{\mathrm{f}}^{2} / E\right)$,

where $B_{\mathrm{m} / \mathrm{m}}$ is a modified mirror/mist boundary constant, $A_{\mathrm{m} / \mathrm{m}}$ that includes the elastic modulus. Equation 5 clearly indicates that the fracture mirror radius is inversely proportion to the stored elastic strain energy at fracture. It suggests that there exists an elastic strain energy criterion for the mirror/mist boundary transition.

Dimensions for the mirror constant, $A_{\mathrm{m} / \mathrm{m}}$, and the fracture toughness are the same, MPa $\mathrm{m}^{1 / 2}$. That dimensional correspondence has caused confusion and led some researchers to erroneously attribute the mirror/mist boundary to the crack achieving the stress intensity value of the fracture toughness, $K_{\mathrm{IC}}$. Actually, $K_{\mathrm{IC}}$ is achieved for the initiating crack at the fracture origin, long before the formation of the mirror/mist boundary as illustrated on the Richter $K_{\mathrm{I}}-\mathrm{V}$ diagram in Fig. 8. This similarity in dimensional units has naturally lead to other attempted associations of the mirror constant with the fracture toughness, further suggesting that a stress intensity criterion other than $K_{\mathrm{IC}}$ may be the criterion for the formation of the mirror/mist boundary.

Whenever a number of fracture mirror constants are compiled for various different glasses along with reliable fracture toughness values, as both Mecholsky and Quinn have done independently, it appears that the fracture mirror constant, $A_{\mathrm{m} / \mathrm{m}}$, is $\sim 2.5$ times the fracture toughness. Table 1 lists the mirror constants and fracture toughness values for three familiar silicate glasses which have been determined by several authors. It is evident that the $A_{\mathrm{m} / \mathrm{m}}$

Table 1 Several fracture mirror constants and fracture toughness values

\begin{tabular}{lcc}
\hline Common glass & Mirror constant, $A_{\mathrm{m} / \mathrm{m}}^{\mathrm{a}}$ & Fracture toughness, $K_{\mathrm{IC}}^{\mathrm{a}}$ \\
\hline Fused silica & 2.22 & 0.79 \\
Soda-lime silica & 1.80 & 0.75 \\
PYREX & 2.08 & 0.71 \\
\hline
\end{tabular}

a The dimensions of both $A_{\mathrm{m} / \mathrm{m}}$, and $K_{\mathrm{IC}}$ are both $\mathrm{MPa} \sqrt{\mathrm{m}}$ values are consistently greater than the $K_{\mathrm{IC}}$ values. In spite of the fortuitous equivalence of dimensions, the mirror/mist constant, $A_{\mathrm{m} / \mathrm{m}}$, is not equal to the fracture toughness, but it is much greater than the fracture toughness. The magnitude of $A_{\mathrm{m} / \mathrm{m}}$ obviously has important implications regarding any dynamic energy criterion for crack growth and formation of the mirror/mist boundary.

The fracture mirror size (the transition from the flat smooth mirror region to the dimpled mist region) is inversely related to the glass strength squared, thus it is only natural to further attempt a similar correlation for the transition from the mist region to the hackle region. Mecholsky has done this with modest success, defining a mist to hackle transition constant, $A_{\mathrm{m} / \mathrm{h}}$ that is larger than $A_{\mathrm{m} / \mathrm{m}}$. This concept certainly has considerable merit, but it has never met with the degree of acceptance as that of the simple mirror/mist relationship. Close examination of Fig. 7 reveals the difficulty. The demarcation between the mist and the hackle is just not as distinct as the well-defined transition between the mirror and the mist. If one closely examines the mist/hackle transition for different angles about the origin, then it is evident that there are places where the mist penetrates deeply into the hackle and ones where it hardly penetrates the hackle at all. Levels of gradation for the transition between the mist and the hackle exist and this presents problems for the measurement of any mist/hackle boundary. This difficulty has inhibited a better definition of the mist/hackle transition.

There is also another related complication in defining the mist to hackle transition or development of the mist/hackle boundary on a glass fracture surface. There are multiple mist/hackle boundaries, first reported by Ramalu et al. but subsequently confirmed and illustrated by Varner and others. For some reason, usually for stronger glass objects, once the hackle region forms, it sometimes degenerates into a secondary mist region which is followed by a second mist/ hackle boundary. This repetitive degeneration and regeneration process of hackle formation may occur several times for a single primary crack. To date, these multiple mist/ hackle boundaries have been of practically no quantitative value as fractographic evidence. However, it is noteworthy that tracing back the secondary hackle lines of the multiple mist/hackle boundaries does identify the location of the fracture origin. It must be concluded that the mist to hackle transition is not well defined, nor is it as well understood as the mirror/mist boundary.

\section{Residual Stress Effects on Fracture Mirrors and Crack Patterns}

Residual stresses in a glass object create greater stored elastic strain energy to drive the propagating crack, or to 
create multiple cracks once fracture is initiated. As illustrated in the Fig. 4 schematic of flat glass fracture, when substantial residual stresses are introduced during strengthening by thermal tempering, then this additional stored elastic strain energy causes the formation of a much greater total crack fracture surface area. Those glasses shatter into numerous almost equiaxed small fragments. The fracture of tempered glass is so remarkable that it has received the special name of dicing, because it produces small fragments much as a kitchen cook creates when dicing vegetables for a soup. From a safety perspective, this dicing fracture mode which produces equiaxed pieces is preferable to the long sharp shards that result from the fracture of fully annealed glass. Dicing has been analyzed in detail by Warren.

Residual stresses also affect the mirror/mist boundary. They alter the shape of the mirror region and change the stress axis intercept for the $A_{\mathrm{m} / \mathrm{m}}$ line on a stress versus the inverse square root of the fracture mirror radius plot. To date, neither of these observations has received substantive application to glass fractography nor a significant amount of theoretical attention either.

The macro-fracture patterns which result in the presence of residual stresses is easily recognized, for the density of cracks increases substantially, but without changing the general macro-crack pattern. This is illustrated in Fig. 10 for the crack patterns of an annealed glass panel and a tempered glass panel, both impacted by high-velocity projectiles. The two starburst crack patterns, which are characteristic of impacts, have significantly different numbers of radial cracks emanating from the central impact point and extending to the panel edges.

\section{The Crack Patterns}

The crack patterns that develop during glass fracture are visible as the traces of the crack or cracks that intersect a surface or a plane such as the $y-z$ plane which is orthogonal to the glass fracture surface $x-y$ plane. The $y-z$ plane is geometrically illustrated in Fig. 5. The trace of the crack occurs when the propagating crack intersects a free surface of the glass object. Trace intersections that reveal the crack patterns include the smooth flat surface of window glass, and the curved surface of a glass container bottle. Below those surfaces, throughout the glass thickness, the crack patterns often directly mimic the geometry of the crack pattern that appears at the glass free surface. However, this may not always be the case as complex states of stress may produce complicated intersecting crack patterns from multiple crack initiation sites.

It is beneficial to view the crack pattern development process in glass through fracture mechanics/energy
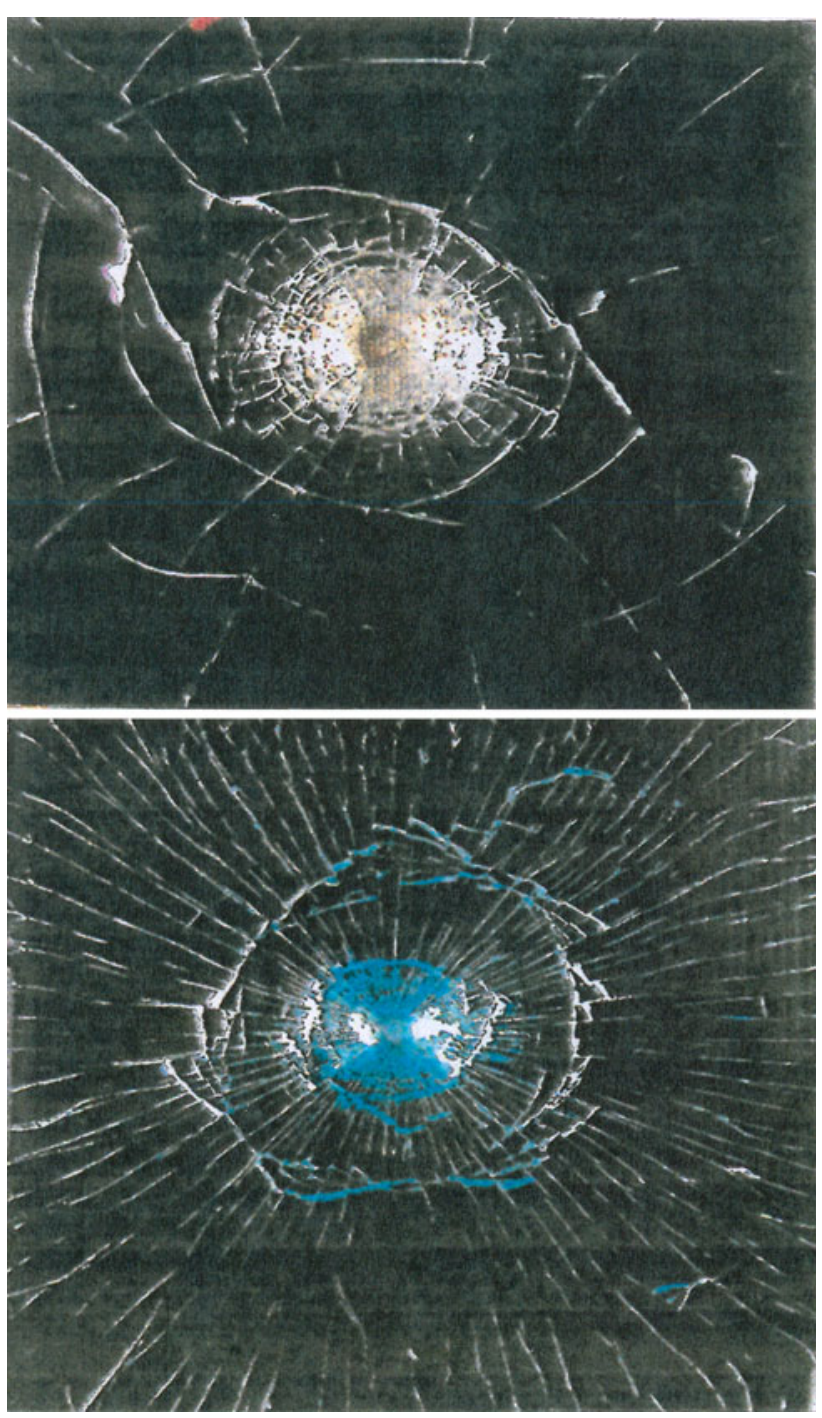

Fig. 10 Starburst impact fractures of an annealed (top) and a tempered (bottom) glass panel after Ahearn

concepts. If one first considers the minimum criterion for crack branching, then the basis for an energy approach to crack pattern development can be established based on the universal energy plot after Broek. This naturally leads into a fundamental understanding of crack patterns, such as those from internal pressure bottle explosions and also for other failures involving various states of stress, many which have been summarized in the Quinn.handbook.

At the fracture origin, the initiation point of crack growth, the stress intensity factor at the crack tip is $K_{\mathrm{IC}}$. Also at that point, the crack growth resistance $R=G_{\mathrm{IC}}$, where $G_{\text {IC }}$ is the critical strain energy release rate, also known as the crack driving force. The crack growth resistance, $R$, is always $2 \gamma$ for the growth of a crack in glass because glass has a flat $R$-curve. $R$ is the same for all values of the crack extension, $\Delta C$. However, it is the steady increase of the $G$ values beyond $G_{\mathrm{IC}}$ at fracture initiation 
that are energetically of paramount importance to the crack pattern development.

Figure 11 illustrates the two quantities, $G$ and $R$, which Broek relates to the classical energy balance of Griffith. The strain energy release rate $G$ is defined as:

$G=\pi \sigma_{\mathrm{f}}^{2} C / E$.

$G$ is equal to $G_{\text {IC }}$ at the point of fracture initiation and also equal to $R$. Note that the expression for $G$ contains the quantity $\left(\sigma_{\mathrm{f}}^{2} / \mathrm{E}\right)$, the stored elastic strain energy as well as $C$, the crack length. The two parameters, $G$ and $R$ are critically important to describe crack extension (growth) processes. They fundamentally determine the available energy for the crack pattern development. The magnitude of the difference between the two parameters, $G-R$, is particularly relevant for $(G-R)$ relates to the kinetic energy of the crack system.

The strain energy release rate, or the crack driving force $G$, is linearly proportional to the crack length $C$ as shown in Eq. 6 and Fig. 11. As a crack grows or extends, the strain energy release rate, the basic driving force for crack extension, continually increases. The longer the crack becomes, the greater is the driving force for even further crack growth. It is this ever increasing crack driving force that causes cracks to propagate completely through many glass objects once fracture initiates.

The fracture mechanics parameters, $G$ and $R$, are graphically presented in Fig. 11 in the form of the universal $(G, R)$ energy versus crack length diagram after Broek. Both $C_{\mathrm{i}}$, the initial crack length and $\Delta C$, the crack growth or extension, are on the ordinate of this diagram. The zero point of this somewhat unusual crack length scale is the initiation point for crack extension. It represents the condition that is achieved at the fracture origin. Figure 11 also

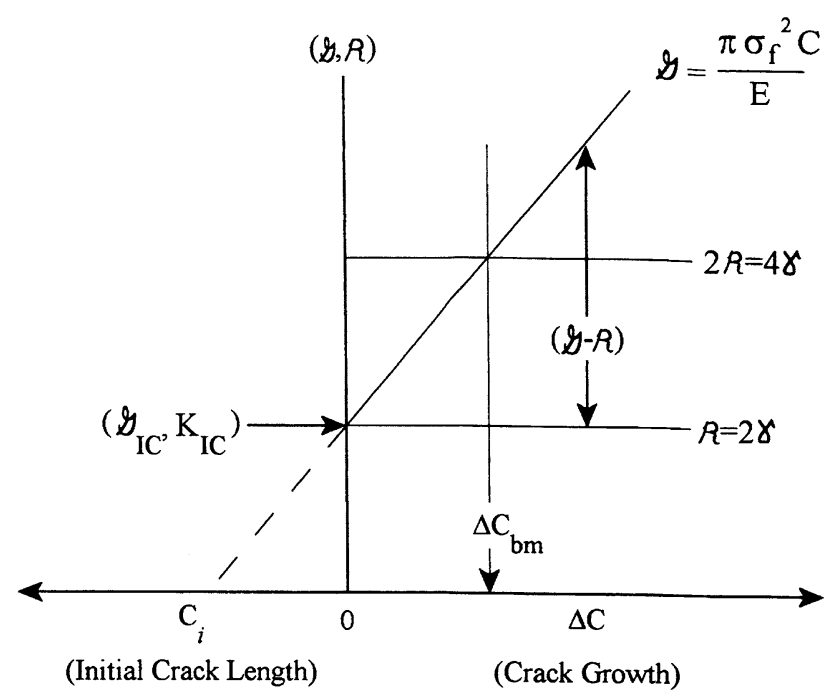

Fig. 11 The $G, R$ versus crack length $\left(C_{\mathrm{i}}\right.$ and $\left.\Delta C\right)$ diagram for fracture illustrates the initial flaw size, $C_{\mathrm{i}}$, which is specified to the left of the zero point on the crack length ordinate. The crack growth, $\Delta C$, is specified to the right of the zero point on the ordinate. The angled straight line is the strain energy release rate, the crack driving force, $G$ which is proportional to the square of the initial strength and increases linearly with increasing crack length $\Delta C$ as previously noted.

A second important point on Fig. 11 is that the crack growth resistance $R$ is constant. Glass has a flat $R$-curve with $R=2 \gamma$ because there are two new fracture surfaces formed as a single crack extends. The solid horizontal line to the right on the ordinate side of the diagram is that flat $R$-curve for glass. When these two parameters, $G$ and $R$, are equated and solved for the stress, they determine the strength, $\sigma_{\mathrm{f}}$, in the form of the classical Griffith Equation. Beyond the origin, the difference of $G$ and $R(G-R)$ is a critically important quantity for the development of the crack pattern during crack propagation. It is the energy available for the kinetics of the crack growth process.

The condition for crack growth is depicted on the ordinate to the right of the abscissa on the universal $(G, R)$ versus crack length, $\Delta C$, rate diagram. The two energy parameters $G$ and $R$ are plotted vertically on the abscissa, while crack length is plotted horizontally on the ordinate. The concept of rate here refers to the crack length and not to time. The rate diagram is the first derivative form of the energy versus crack size diagram that has an energy maximum at the $C$ value of zero for the Griffith stability condition.

Figure 11 can be applied to estimate the minimum primary crack length that is necessary for crack branching, or bifurcation on a quasi-static energy basis. When a single crack branches (forks or bifurcates) then it forms two new secondary cracks. The two secondary cracks have four fracture surfaces, twice as many as the single crack. Therefore, the minimum value of $G$ that is required for a single primary crack with two surfaces to bifurcate into two secondary cracks with four fracture surfaces must be $2 R$ or $4 \gamma$. On Fig. 11 this condition is shown as $\Delta C_{\mathrm{bm}}$ on the ordinate where the "bm" subscript designates the "branching minimum" value. A minimum total strain energy release rate of $4 \gamma$ is a necessary, but not sufficient, condition for crack branching. In actuality, the strain energy release rate for bifurcation must be greater than that specified for the quasi-static condition specified by $\Delta C_{\mathrm{bm}}$. The reason is the kinetic energy requirements of the total crack system of the glass object.

A minimum requirement of $G=4 \gamma$ at a crack growth of $\Delta C_{\mathrm{bm}}$ makes crack branching possible. Note that it is only achieved after some initial amount of primary crack growth. This extent of primary crack growth is shown in Fig. 11 as $\Delta C_{\mathrm{bm}}$. It illustrates why growing cracks will only bifurcate after extension as a single primary crack. 
It is equally important to realize that the true minimum strain energy release rate for a single primary crack to fork, or to bifurcate into two cracks must actually be for values of $G \geq 2 R$ or $4 \gamma$. This is because the previous description is for a quasi-static situation, but there is also kinetic energy associated with the extension of the single primary crack as well as with the two secondary crack branches. Because of this kinetic energy requirement, the $G \geq 2 R$ criterion for $\Delta C_{\mathrm{bm}}$ must be the branching minimum crack growth $\Delta C_{\mathrm{bm}}$ or a strain energy release rate, $G_{\mathrm{bm}}$ for crack bifurcation in glass.

For further illustrative purposes of the usefulness of the quasi-static $(G, R)$ versus $\Delta C$ diagram, Fig. 12 contrasts the $\Delta C_{\mathrm{bm}}$ values for a low-strength glass specimen $\left(C_{\mathrm{ils}}\right)$ and for a high-strength glass specimen $\left(\mathrm{C}_{\mathrm{ihs}}\right)$. This slightly complicates the $(G, R)$ versus $\Delta C$ diagram with an extra line, but it explains the effect of strength level on the extent of crack growth before bifurcation occurs. Note that the highstrength specimen (hs) achieves the condition of $G \geq 2 R$ for a much smaller $\Delta C_{\mathrm{bm}}$ value than the low-strength specimen (ls). This illustrates why high-strength glass fractures fork at a much smaller $\Delta C$ values after crack initiation and must also relate to the smaller $R_{\mathrm{m} / \mathrm{m}}$ boundaries in high-strength glass objects. High-strength glasses not only form smaller mirrors, but they bifurcate much sooner because of the much steeper $G$ slope on the $(G, R)$ diagram.

The quasi-static $(G, R)$ versus $\Delta C$ diagram can also be applied to explain why low-strength glass objects never exhibit crack branching when they fail, nor do many of them develop definitive mirror/mist/hackle boundaries either. This is because the $C_{\mathrm{i}}$ value for a low strength is so far to the left of the zero point on the ordinate of the universal $(G, R)$ versus $\Delta C$ diagram that the slope of $G$, $\partial G / \partial \Delta C$, is so small that the value of $G$ remains too low before the glass object is completely broken in two.

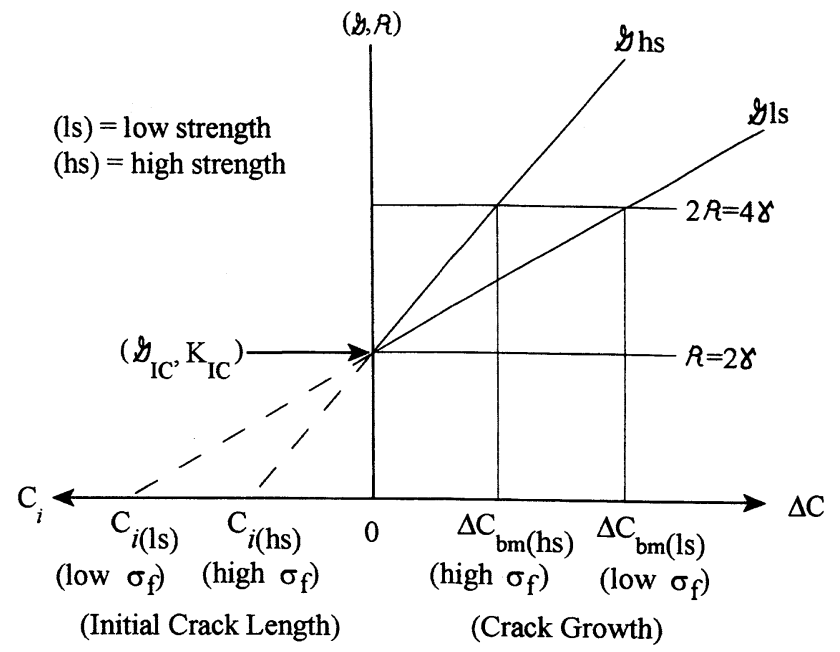

Fig. 12 The $G$ difference between small and large cracks
Dimensionally, the specimen is smaller than the minimum length for the mirror criterion to be achieved. The primary crack propagates completely through the glass object, but it is never is able to fork, or branch because the $\Delta C_{\mathrm{bm}}$ occurs for a $\Delta C$ value which is larger than the actual dimensions of the glass object in the direction of crack growth.

\section{Angles Between Branching or Forking Cracks}

This lack of a mirror/mist boundary also occurs for glass nano-fibers, also for the dimensional reason. The angle between the two branches of a bifurcating crack is also an important feature of glass crack patterns. The different branching angles which are observed for bifurcation under different states of stress have never been mathematically specified in a closed form analytical solution. However, Quinn has summarized the experimental observations in the Fig. 13 diagram from his fractography handbook. It schematically depicts of the effects of the biaxial nature of the stress state on the observed bifurcation angles. From Quinn's summary diagram, it is evident that the state of the biaxial stress has a profound effect on the angle of crack branching. Reconstructed broken glass objects are able to specify these forking angles, which can in turn be used to describe the state of stress of the glass object at fracture initiation.

\section{The Bifurcation of Pressure Fractures and the Crow's Feet Fracture Pattern}

One form of multiple crack bifurcation that is of continuing interest is the "crow's feet" crack pattern that develops

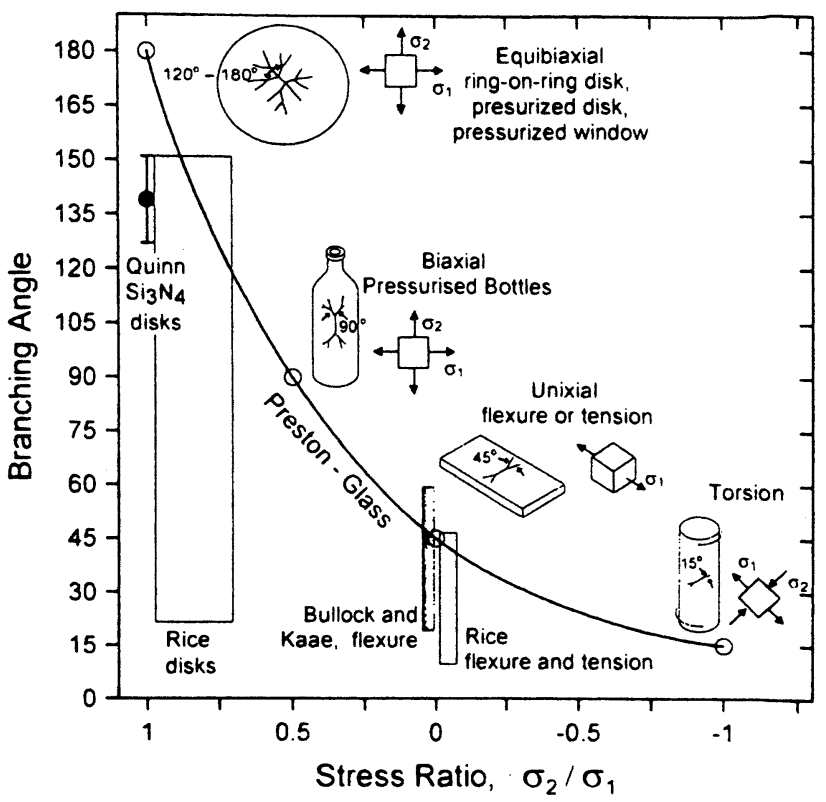

Fig. 13 Crack bifurcation (branching) angles summarized by Quinn 
during bottle explosions or from the wind pressure against a flat glass window during a severe wind storm such as a hurricane. Similar cracking patterns have also been shown to develop for disc strength testing specimens, thus these form under biaxial stresses.

Figure 14, after Kepple and Wasylyk illustrates the internal pressure failure crack patterns for two reconstructed bottle "explosions," the left a low-pressure failure and the right a high pressure one. Bottle pressure fractures usually, but not always, originate from a flaw on the outside barrel of the bottle. This is because the hoop stress is twice the longitudinal stress for a thin-walled cylinder as noted in Quinn's Fig. 13. Once initiated, the primary crack then propagates vertically both up and down the barrel of the bottle away from its origin. At some crack length $>\Delta C_{\mathrm{bm}}$, it forks or branches with the appearance of "crow's feet". "Crow's feet" form at both the top and the bottom of the vertical crack, although depending on the origin location relative to the bottle height may develop more fully on one. The fracture origin is half-way between the top fork and the bottom fork of the vertical crack. Two mirror/mist/hackle patterns can usually be found on the bottle wall thickness when the bottle is reconstructed from the broken shards as it has been in Fig. 14. The branching also confirms the two crack growth directions, for after fracture initiation the crack growth direction is toward the forking event.

This internal pressure failure crack pattern is illustrated schematically in Fig. 15 for four different internal bottle pressure failures, increasing from the left to the right. The "crow's feet" can be explained by the basic $(G, R)$ crack length diagram, albeit it a slight more complicated version than was depicted in Figs. 11 and 12. First is that the forks of the "crow's feet" only occur after some amount of crack extension which must be $>\Delta C_{\mathrm{bm}}$. Second is that the higher is the internal pressure causing the fracture, the shorter is the distance between the two "crow's feet" on the vertical barrel cracks. The value of $(G-R)$ that is required for the forking formation is achieved for a smaller $\Delta C$, similar to the explanation for branching in Fig. 12. Finally, the greater the internal pressure or the stress of the failure, the greater is the number of multiple forkings, or branchings of the primary crack, that is there are more feet on the "crow's feet" when the quantity $(G-R)$ is greater as there is more energy is available. All of these are explained qualitatively by the $(G, R)$ versus the $C, \Delta C$ diagram.

That crack branching or "crow's feet" formation only occurs after some extension of the primary crack was previously explained in terms of the $(G, R)$ diagram in Fig. 10 as specified in terms of the strain energy release rate, $G$, and the crack growth resistance, $R$. The $\Delta C_{\mathrm{bm}}$ is only a minimum energy criterion for crack branching that does not include the kinetic energy requirements. The

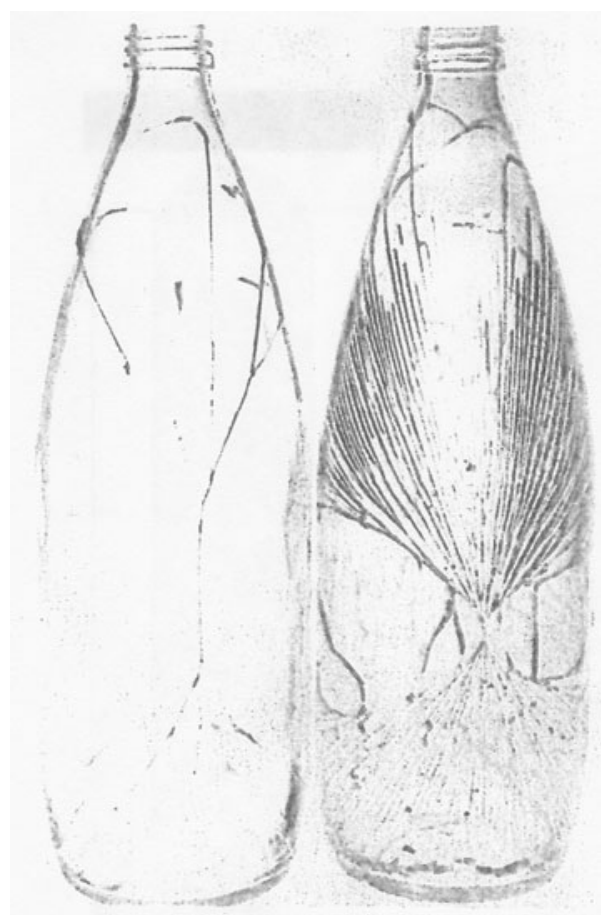

Fig. 14 Low pressure and high pressure bottle fractures after Kepple and Wasylyk

$\Delta C_{\mathrm{bm}}$ is specified when $G=2 R=4 \gamma$. The two strain energy release rate lines, $G_{\mathrm{ls}}$ and $G_{\mathrm{hs}}$ in Fig. 11, may be thought of as a low-pressure fracture and a high-pressure fracture. It is evident that the high-pressure (strength) fracture reaches $2 R$ or $4 \gamma$ for a much smaller $\Delta C$ of crack extension. It is the reason for a shorter vertical crack between the "crow's feet" of the vertical crack, as the fracture pressure (stress) is higher.

Quinn has pointed out that there have been efforts to address the $\Delta C$ for branching issue similar to the fracture mirror constant by specifying a branching constant. However, he qualifies that point, suggesting that maybe this branching constant approach is not absolutely fundamental. I believe that Quinn is correct. The quasi-static approach, although valuable to explain the phenomenon, does not specify the kinetic energy of the primary crack or the two new cracks. However, the $(G, R)$ diagram does explain the shorter branching distance, $\Delta C_{\mathrm{b}}$ branch, for higher pressure (stress) fractures.

The number of feet on the "crow's foot" has not been numerically defined by the $(G, R)$ diagram. However, it can be considered from the viewpoint of the $(G-R)$ energy on the universal diagram. The greater the pressure at fracture, the larger is the number of "crow's feet" or multiple bifurcating cracks at the ends of the vertical crack. This is because the strain energy release rate, $G$, increases much more rapidly for a high-pressure failure than it does for a low pressure one. This provides more energy for formation 
Fig. 15 Schematic of the effect of pressure on bottle fractures increasing pressure from left to right
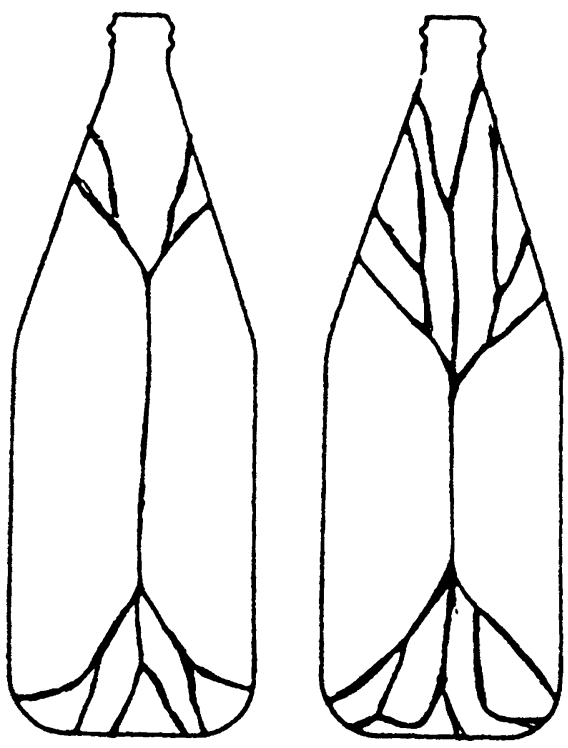

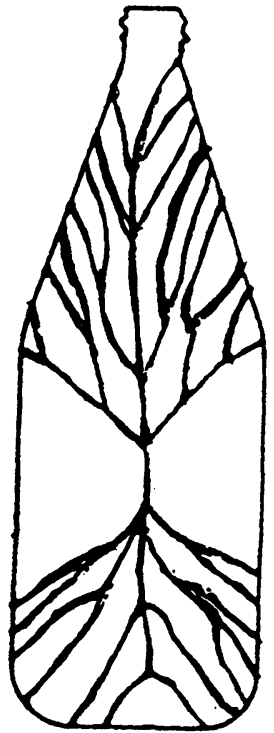

of the (crow's feet). It will continue to increase more rapidly beyond the line of $R=4 \gamma$. That increase will lead the $G$ value to reach $3 R, 4 R$, etc. sooner, creating shorter $\Delta C$ s between the multiple branches more rapidly, thus creating more branches or "crow's feet." One might also note that a very low-pressure fracture may never achieve the higher multiples of $R$ on this diagram and the result may be that no multiple "crow's feet" will form beyond the original branch of the primary crack.

\section{Thermal Stress Crack Patterns}

Crack branching concepts are readily applied to thermal stress cracks such as those which develop in the rapid cooling of warm bottles and in unevenly heated large glass panel windows. Thermal stress cracks initiate when there is a change or a gradient in the temperature and the dimensional changes of the glass object are restrained. For bottles this might occur during the introduction of a bottle containing hot liquid into a refrigerator, such that the outer surface is colder than the bottle interior. For windows, this may occur if there is an overhang shading a window on the sunny-side of a building. For the latter, the top of the window is in the shade while the lower portion becomes heated by the sun. This creates a tension at the cold top of the window that balances the compression at the warmer bottom. A thermal shock crack initiates in the tensile stress at the window top then propagates as a primary crack toward the bottom before branching.

As thermal stress cracks gradually only achieve the failure stress after subcritical crack growth, the $C_{\mathrm{i}}$ and thus the $\Delta C_{\mathrm{bm}}$ for thermal stress cracks are usually quite large. For this reason, a single thermal stress crack usually propagates a long distance before it exceeds $\Delta C_{\mathrm{bm}}$ and forms branches. This scenario determines the characteristic pattern for a thermal stress crack. It is usually a long single crack that branches after considerable extension. In the case of the window, the primary single crack may extend more than half the height of the window before it finally branches. A thermal stress crack in a bottle may extensively meander about the bottle contours before finally branching or forking, if it branches at all.

\section{Other Cracking Patterns Observed for Glass Fractures}

There are numerous other types of interesting crack patterns that develop for the different causes of fracture of glasses. The length of this article does not permit every one of them to be described and explained via fracture mechanics concepts. However, they certainly merit brief descriptions. Most are familiar with the Hertzian cone crack when a lowenergy projectile impacts a glass object such as a window. Perhaps some of the readers were responsible for creating these with a BB gun in their youth? This is not really a complete fracture for the cracking arrests because of insufficient energy to complete break the plate glass window in two, but the conical pattern is a familiar one.

Highly energetic impact crack patterns are readily identified from the multiple radiating star-like cracks that emanate from the point of impact and also the numerous circular or circumferencial cracks which are generated. They lend a "spider's web" type of appearance to the crack pattern. Figure 10 illustrated a couple of these that were presented to show the greater amount of cracking from the viewpoint of annealed versus tempered flat glass panels. If the impact is from a sharply pointed object, then the radial 
cracks appear to emanate from a point. When the impact is by a blunt object, then there is an impact crush zone from which the radial cracks emanate. Severe spalling also frequently occurs on the back side of glass panels subjected to high-energy impacts. For high-velocity projectiles, the numbers of radial cracks have been found to be proportional to the kinetic energy of the projectile, once again illustrating the importance of the energy contributions to the development of crack patterns.

\section{Summary}

The features of the fracture surface and the crack patterns which develop when glass breaks have been presented. The roles of glass strength and the elastic strain energy are emphasized within a fracture mechanics and an energy perspective, the latter on the universal energy diagram for crack growth. Aspects of the fracture topography and crack patterns of glass were discussed within these perspectives.

Acknowledgments The author acknowledges the discussion of these concepts with colleagues and former students. It is possible to overlook individuals, for which he apologizes in advance. I would be remiss if I did not acknowledge a 1970s instruction by R. L. Stewart now at Corning on how to reconstruct broken bottles. H. Chandan of Bell Labs, Norcross and N. Shinkai of Asahi Glass were instrumental in discerning many fracture patterns. More recently, D. Ahearn of ESI, J. Ladner, now a practicing lawyer, and S. E. Jones were important in cooperative studies of the impact fractures of flat glass. Discussions with G. D. Quinn and M. Barkey on the fundamentals of fracture are also appreciated. Finally, he is indebted to J. D. Mackenzie and G. E. Rindone for teaching him about glass.

\section{Books Addressing Fracture}

Bradt, R.C., Tressler, R.E.: Fractography of Glass. Plenum Pub. Corp., New York, NY (1994)

Broek, D.: Elementary Engineering Fracture Mechanics. Martinus Nijhoff Pub., Dordrecht, The Netherlands (1974)

Frechette, V.D.: Failure analysis of brittle materials. In: Adv. in Ceramics, vol. 28. The Amer. Cer. Soc., Westerville, OH (1990)

Hull, D.: Fractography, Observing, Measuring and Interpreting Fracture Surface Topography. Cambridge Univ. Press, Cambridge, GB (1999)

Quinn, G.D.: Fractography of Ceramics and Glasses. NIST Spec. Tech. Pub. 960-16, NIST, Gaithersburg, MD (2007)

Roulin-Moloney, A.C.: Fractography and Failure Mechanisms of Polymers and Composites. Elsevier Applied Science, London, GB/New York, NY (1988)

\section{Conference Proceedings Addressing the Fractography of Glass and Ceramics}

Conferences at Alfred University, Alfred, NY, USA. These have been organized by J. Varner and colleagues approximately every four years for $\sim 20$ years and have been published as Adv. in Ceramics by The American Ceramic Society

Conferences in Slovakia organized by J. Dusza and colleagues, also approximately every 4 years for $>10$ years, of the IMR in Kosice, Slovakia. These volumes have been published by Trans Tech Pub, Zurich, Switzerland

\section{Archival Journal Manuscripts and Individual Papers}

Abdel-Latif, A.I.A., Bradt, R.C., Tressler, R.E.: Dynamics of fracture mirror boundary formation in glass. Int. J. Fract. 13(3), 349-359 (1977)

Ahearn III, D.L., Ladner, J.L., Jones, S.E., Wright, R.E., Bradt, R.C.: Fracture patterns of impact resistant glass panel laminates with annealed and heat strengthened glass plates. In: Adv. in Cer. Trans., vol. 199, pp. 383-396 (2007)

Ball, M.J., Landini, D.J., Bradt, R.C.: The fracture mist region in a soda-lime-silica float glass. In: Fractography of Ceramic and Metal Failures, pp. 110-120. ASTM STP-827, ASTM, Philadelphia, PA (1984)

Cantwell, W.J., Roulin-Moloney, A.C.: Fractography and failure mechanisms of unfilled and particulate filled epoxy resins. In: Fractography and Failure Mechanisms of Polymers and Composites, pp. 233-285. Elsevier Applied Science, London, GB and New York, NY (1988)

Chandan, H.C., Bradt, R.C., Rindone, G.E.: Dynamic fatigue of float glass. J. Am. Ceram. Soc. 61(5-6), 207-210 (1978)

Chandan, H.C., Parker, R.D., Kalish, D.: Fractography of optical fibers. In: Bradt, R.C., Tressler, R.E. (eds.) Fractography of Glass, pp. 143-206. Plenum Pub. Co., New York, NY (1994)

CORNING, ACerS Technical Achievement Award, American Ceramic Society Bulletin, vol. 89, no. 8, 40, 41 (2010)

Freiman, S.W., Wiederhorn, S.M., Mecholsky, J.J.: Environmentally enhanced fracture of glass: a historical perspective. J. Am. Ceram. Soc. 92(1), 1-112 (2009)

Johnson, J.W., Holloway, D.G.: On the shape and the size of the fracture zones on glass fracture surfaces. Philos. Mag. 42, 731743 (1966)

Kepple, J.B., Wasylyk, J.S.: Fractography of glass containers. In: Bradt, R.C., Tressler, R.E. (eds.) Fractography of Glass. Plenum Press, New York, NY (1994)

Kurkjian, C.R.: Mechanical strength of glasses-studies then and now. In: The Glass Researcher, vol. 11, no. 2, pp. 1-6 (2002)

McMaster, R.A., Shetterly, D.M., Bueno, A.G.: Annealed and tempered glass. In: Engineered Materials Handbook, vol. 4, pp. 453-459. ASM International, Materials Park, OH (1991)

Mecholsky, J.J.: Quantitative fractography analyses of fracture origins in glass. In: Bradt, R.C., Tressler, R.E. (eds.) Fractography of Glass, pp. 37-73. Plenum Press, New York, NY (1994)

Michalske, T.A.: Quantitative fracture surface analysis. In: Engineered Materials Handbook, vol. 4, pp. 652-662. ASM International, Materials Park, OH (1991)

Preston, F.: The mechanical properties of glass. JAP 13, 623-634 (1942)

Ramalu, M., Bradt, R.C., Kobayasahi, A.S.: A dynamic interpretation of multiple-mist/hackle boundary formation on glass fracture surfaces. In: Varner, J.R., Frechette, V.D. (eds.) Adv. in Ceramics, vol. 22, pp. 215-228. Amer. Cer. Soc., Westerville, $\mathrm{OH}(1988)$ 
Redner, A.S., Mognato, E., Schiavonato M.: Correlation between strength and measured residual stress in tempered glass products. In: Bunch, J., Mitchell, M.R. (eds.) ASTM STP 1497, "Fatigue and Fracture Testing", pp. 85-94. Philadelphia, PA (2005)

Shinkai, N., Bradt, R.C., Rindone, G.E.: The fracture toughness of fused silica and float glass at elevated temperatures. J. Am. Ceram. Soc. 64(7), 426-430 (1981)

Shinkai, N., Sakata, H.: Fracture mirrors in Columbia resin, CR-39. J. Mater. Sci. 13, 415-420 (1978)
Varner, J.R.: Descriptive fractography. In: Engineered Materials Handbook, vol. 4, pp. 635-644. ASM International, Materials Park, OH (1991)

Warren, P.D.: Fragmentation of thermally strengthened glass. In: Varner, J.R., Quinn, G.D. (eds.) Adv. in Ceramics, vol. 122, pp. 389-402. Amer. Cer. Soc., Westerville, OH (2000)

Wiederhorn, S.M., Bolz, L.H.: Stress corrosion and static fatigue of glass. J. Am. Ceram. Soc. 53(10), 543-548 (1970)

Yoffe, E.H.: The moving griffith crack. Philos. Mag. 14, 739-750 (1951) 